\section{The World Health Organization} excludes Mycobacterium tuberculosis from the 2017 priority pathogens list

To the Editor: On 27 February 2017 the World Health Organization (WHO) published the first priority pathogens list (PPL) for research and development of new antibiotics, which according to the WHO identifies 'the most important resistant bacteria at a global level for which there is an urgent need for new treatments'. Selection criteria for prioritisation included: all-cause mortality, healthcare and community burden, prevalence of resistance, 10-year trend of resistance, transmissibility, preventability in hospital and community settings, and treatability and current pipeline, thereby making the exclusion of Mycobacterium tuberculosis from the PPL inconceivable, justifiably provoking the international medical and scientific fraternity. Drug-resistant tuberculosis (DR-TB) is a major global epidemic, with 0.5 million cases occurring each year. ${ }^{[1]}$ Extensively DR-TB (XDR-TB), in particular, is of major concern, with poor treatment success rates of $<40 \%$ in most patient populations, and mortality rates of $50-80 \%$. $^{[2-6]}$

The exclusion of $M$. tuberculosis from the PPL creates the impression that DR-TB is not a public health threat, undoubtedly preventing prioritisiation of $\mathrm{TB}$ research by policy-makers. This is not negotiable. It is noteworthy that the WHO finally dedicated resources to identify a PPL. However, central to the integrity of the report is surely the inclusion of $M$. tuberculosis as a key priority pathogen. The drug development pipeline for anti-TB drugs is narrow. Existing drugs are associated with serious adverse effects, such as irreversible ototoxicity, nephrotoxicity, debilitating nausea and psychosis. After five decades, two new anti-TB drugs, bedaquiline and delamanid, were developed, with an accelerated approval of bedaquiline.

DR-TB remains an ongoing global health threat, with high levels of mortality and persistent limited treatment options. Other new options include pretomanid, and older repurposed drugs such as clofazimine. The combination of bedaquiline, pretomanid and linezolid was recently shown to be very effective in the NIX-TB clinical trial, reinforcing the positive impact of research. Seventy-two patients were recruited from April 2015; 65\% of these patients had XDR-TB, while the remaining patients had multidrug-resistant TB (MDR-TB) and were either not responding to treatment or could not tolerate the side-effects. Just over half were HIV-positive. Forty patients have completed the 6-month trial and 31 have had their 6 -monthly follow-up examination. Of these 31 patients, only one relapsed. ${ }^{[7]}$

The release of the WHO PPL coincides with the report 'Mortality and causes of death in South Africa, 2015: Findings from death notification', which highlights that 'tuberculosis was the leading cause of death in both males and females in 2015, in South Africa. ${ }^{\text {[ }}{ }^{[8]}$
Exclusion of TB in the WHO PPL negates acceleration of research and development efforts in DR-TB treatment. This is a violation of fundamental human rights, and will likely impede access to effective drugs for this deadly disease.

By adopting the decision to exclude TB in the PPL, the WHO runs the risk of being viewed as purveyors of ill-informed science. We therefore urgently call on the WHO to facilitate a timely review of the impact of M. tuberculosis resistance globally, which certainly warrants its inclusion in the global PPL.

\section{N Padayatchi}

Centre for the AIDS Programme of Research in South Africa (CAPRISA), and CAPRISA-MRC TB-HIV Pathogenesis Unit, Durban, South Africa

\section{S Mahomed}

Centre for the AIDS Programme of Research in South Africa (CAPRISA), Durban, South Africa

sharana.mahomed@caprisa.org

\section{O'Donnell}

Centre for the AIDS Programme of Research in South Africa (CAPRISA), Durban, South Africa; and Allergy and Critical Care Medicine, and Department of Epidemiology, Mailman School of Public Health, Columbia University Medical Center, NY, USA

\section{F Conradie}

South African HIV Clinicians Society, Johannesburg, South Africa

\section{K Naidoo}

Centre for the AIDS Programme of Research in South Africa (CAPRISA), and CAPRISA-MRC TB-HIV Pathogenesis Unit, Durban, South Africa

1. World Health Organization. Global Tuberculosis Report. Geneva: WHO, 2015.

2. O’Donnell MR, Padayatchi N, Kvasnovsky C, et al. Treatment outcomes for extensively drug-resistant tuberculosis and HIV co-infection. Emerg Infect Dis 2013;19(3):416-424. http://dx.doi.org/10.3201/ eid1903.120998

3. Pietersen E, Ignatius E, Streicher EM, et al. Long-term outcomes of patients with extensively drug resistant tuberculosis in South Africa: A cohort study. Lancet 2014;383(9924):1230-1239. http://dx.do org/10.1016/S0140-6736(13)62675-6

4. Falzon D, Gandhi N, Migliori GB, et al. Resistance to fluoroquinolones and second-line injectable drugs: Impact on multidrug-resistant TB outcomes. Eur Respir J 2013;42(1):156-168. http://dx.doi. org/10.1183/09031936.0013471

5. Gandhi NR, Moll A, Sturm AW, et al. Extensively drug-resistant tuberculosis as a cause of death in patient co-infected with tuberculosis and HIV in a rural area of South Africa. Lancet 2006;368(9547):1575-1578 http://dx.doi.org/10.1016/S0140-6736(06)69573-1

6. Shah NS, Auld SC, Brust JCM, et al. Transmission of extensively drug-resistant tuberculosis in South Africa. N Engl J Med 2017;376(3):243-253. http://dx.doi.org/10.1056/NEJMoal604544

7. Conradie F, Diacon H, Everitt D, et al.The NIX-TB trial of pretomanid, bedaquiline and linezolid to treat XDR-TB. Abstract, Conference on Retroviruses and Opportunistic Infections. Seattle, USA, 13 - 16 Feb a 2017. htp/ww bedaquiline-and-linezolid-treat-xdr-tb (accessed 25 April 2017).

Statistics South Africa. Mortality and causes of death in South Africa, 2015: Findings from death notification. Pretoria: Stats SA, 2017. www.statssa.gov.za (accessed 20 April 2017).

S Afr Med J 2017;107(6):466. DOI:10.7196/SAMJ.2017.v107i6.12474 